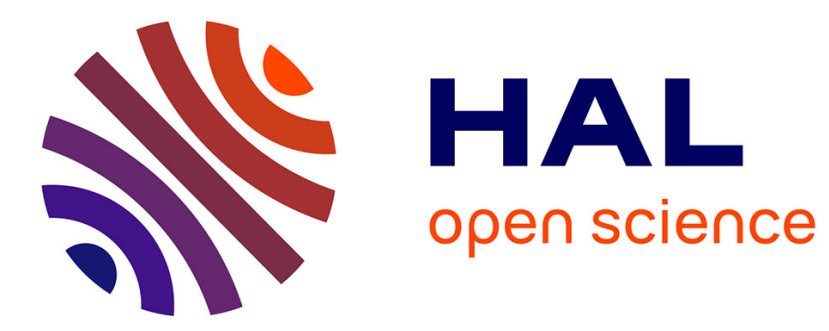

\title{
Magnetic behaviour of the new hydride CePtAlHx
}

Jean-Louis Bobet, Bernard Chevalier, François Weill, Jean Etourneau

\section{To cite this version:}

Jean-Louis Bobet, Bernard Chevalier, François Weill, Jean Etourneau. Magnetic behaviour of the new hydride CePtAlHx. Journal of Alloys and Compounds, 2002, 330-332, pp.373-375. 10.1016/S09258388(01)01578-X . hal-00070926

\section{HAL Id: hal-00070926 \\ https://hal.science/hal-00070926}

Submitted on 30 May 2012

HAL is a multi-disciplinary open access archive for the deposit and dissemination of scientific research documents, whether they are published or not. The documents may come from teaching and research institutions in France or abroad, or from public or private research centers.
L'archive ouverte pluridisciplinaire HAL, est destinée au dépôt et à la diffusion de documents scientifiques de niveau recherche, publiés ou non, émanant des établissements d'enseignement et de recherche français ou étrangers, des laboratoires publics ou privés. 


\section{Magnetic behaviour of the new hydride CePtAlH}

Bobet J.-L., Chevalier B., Weill F., Etourneau J.

Published in Journal of Alloys and Compounds 2002, vol. 330-332, p. 373-375.

\section{Abstract :}

CePtAl absorbs hydrogen up to a concentration of $1.1(1) \mathrm{H} \mathrm{mol}^{-1}$ at room temperature. The formation of this hydride $\mathrm{CePtAlH}_{1.1}$ that loses hydrogen in air corresponds to a plateau pressure of $0.08-0.1 \mathrm{MPa}$. Its absorption-desorption is practically reversible which can present a potential interest for applications (but only a few due to the high price of the material) around room temperature and normal pressure. Hydrogenation of CePtAl induces both: (i) a structural transition but the structure of the hydride is unknown at present; (ii) an increase of its ferromagnetic character; the hydride has a Curie temperature $T_{\mathrm{c}}=11.6(2) \mathrm{K}$ twice greater than that determined for the initial intermetallic (i.e. $5.6(2) \mathrm{K})$.

\section{Introduction}

Recently, we have shown that the hydrogenation of the CeNiAl compound induces both a structural transition from the hexagonal ZrNiAl-type to the hexagonal $\mathrm{AlB}_{2}$-type for the hydride $\mathrm{CeNiAlH}_{1.93}$ and a valence transition for cerium from tetravalent to trivalent state [1]. The hydrogenation of CeNiAl leads to an expansion of its molar volume favouring the occurrence of spin fluctuation behaviour below $7 \mathrm{~K}$ for the hydride. Encouraged by this interesting result, we are now studying the hydrogen absorption-desorption properties of the equiatomic CePtAl compound. This ternary aluminide crystallises in the orthorhombic TiNiSi-type structure where Ce-atoms form a network of chains parallel to the $a$-axis [2]. Neutron powder diffraction experiments performed on CePtAl reveal a complex magnetic phase diagram: three successive transitions are detected respectively at $T_{\mathrm{c}}=5.9 \mathrm{~K}, T_{2}=4.3 \mathrm{~K}$ and $T_{3}=2.2 \mathrm{~K}$ [3]. But this study shows that the magnetism of CePtAl is dominated by a ferromagnetic component $1.35(4) \mu_{\mathrm{B}}$ at $1.5 \mathrm{~K}$ of the ordered Ce-moment. This original behaviour results from the existence of a large magnetic anisotropy caused by competition between magnetic exchange interactions existing respectively in the $\mathrm{Ce}-\mathrm{Ce}$ chains and between themselves [4]. Moreover, specific heat measurements suggest that the reduction of the ordered Ce-moment found in CePtAl can be explained by the existence of the Kondo effect [5]. The magnetic and Kondo interactions are governed by the $\mathrm{Ce}-\mathrm{Ce}$ interatomic distances $\left(d_{\mathrm{Ce}-\mathrm{Ce}}\right)$; in this view it is interesting to modify these distances for instance by insertion of hydrogen in the lattice.

In this paper, we report on the synthesis of the hydride CePtAlH $\mathrm{H}_{x}$ and on its characterisation using X-ray powder diffraction and magnetization measurement.

\section{Experimental details}

CePtAl sample was prepared by arc-melting stoichiometric amounts of pure elements ( $3 \mathrm{~N}$ for Ce, $3 \mathrm{~N} 5$ for Pt and $5 \mathrm{~N}$ for $\mathrm{Al}$ ) under a protective Ar-atmosphere followed by an annealing treatment under vacuum at $1073 \mathrm{~K}$ for 1 month. Its characterisation by electron microprobe analysis reveals a perfect chemical homogeneity. Its checking by X-ray powder diffraction (Philips PW 1050 diffractometer, Cu-Ka radiation) confirms that CePtAl crystallises in the orthorhombic TiNiSi-type with unit cell parameters $a=0.7208(5) \mathrm{nm}, b=0.4481(5) \mathrm{nm}$ and $c=0.7740(5) \mathrm{nm}$ in agreement with those reported previously [2].

Hydrogen absorption-desorption measurements were performed using the apparatus described previously [6]. CePtAl sample was crushed (grain size $\leq 100 \mu \mathrm{m}$ ), and then exposed to hydrogen gas. The amount of $\mathrm{H}$-atom absorbed was determined volumetrically by monitoring pressure changes in a calibrated volume.

Magnetization measurements were performed using a Superconducting Quantum Interference Device (SQUID) magnetometer in the temperature range $1.8-300 \mathrm{~K}$ and applied fields up to $5 \mathrm{~T}$. 


\section{Results and discussion}

Without any thermal activation treatment, CePtAl absorbs hydrogen at room temperature. Its hydrogen absorptiondesorption capacities are strongly dependent to the number of hydriding-dehydriding cycles (Fig. 1): (i) at the initial cycle $n=1$, CePtAl starts to absorb hydrogen at a pressure of $0.8 \mathrm{MPa}$; (ii) for the second one, the amount of $\mathrm{H}$-atom absorbed varies almost linearly with the hydrogen pressure; (iii) finally, one can observe that the sample is successfully activated after three hydriding-dehydriding cycles. At $295 \mathrm{~K}$, CePtAl absorbs hydrogen up to a concentration of $1.1(1) \mathrm{H} \mathrm{mol}^{-1}$ under a pressure of $1.1 \mathrm{MPa}$ (Fig. 2). The plateau pressure at this temperature in the range $0.08-0.1 \mathrm{MPa}$ corresponds to the formation of the hydride CePtAlH $\mathrm{H}_{1.1(1)}$ that loses hydrogen in air (as reported on Fig. 3). Its absorption-desorption is practically reversible.

Pressure-composition-temperature (PCT) curves realized at various temperatures for CePtAl are presented on Fig. 2. For this study, the sample was hydrided-dehydrided three times before the shown experiments were carried out; so these results are expected to represent the thermodynamically stable state. It appears clearly that the increase of temperature induces a significant decrease of the hydrogen content of the $\mathrm{CePtAlH}_{x}$ hydride $(x \cong 0.9(1)$ at $373 \mathrm{~K})$ and increase of the plateau pressure. The rather large plateau slope observed at $373 \mathrm{~K}$ can be attributed to sample temperature inhomogeneities. The thermodynamic data calculated according to the Van't Hoff equation are $\Delta H=-24$ $\mathrm{kJ} \mathrm{mol}{ }^{-1}$ and $\Delta S=180 \mathrm{~J} \mathrm{~mol}^{-1} \mathrm{~K}^{-1}$.

The X-ray powder pattern of CePtAl, given in Fig. 3, is completely indexed on the basis of the orthorhombic TiNiSitype structure. On the contrary the pattern relative to $\mathrm{CePtAlH}_{1.1}$ hydride, characterising a well-crystallised material, clearly shows that hydrogenation leads to a structural transition (Fig. 3). This last structure is unknown at present but under study using transmission electron microscopy. After exposure in air for 5 days at room temperature, the hydride CePtAlH $\mathrm{H}_{1.1}$ is partially decomposed; X-ray diffraction analysis reveals the occurrence of a mixture containing

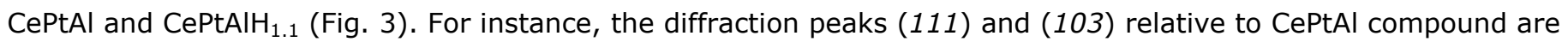
clearly observed after the exposure. This result agrees with the low dissociation pressure $\cong 0.1 \mathrm{MPa}$ at $295 \mathrm{~K}$ (Fig. 2) of this hydride. After desorption ( $0.05 \mathrm{MPa}$ for $1 \mathrm{~h}$ ) the X-ray diffraction analysis reveals the occurrence of a single phase which is similar to CePtAl (as expected).

Magnetization measurements were performed on the hydride CePtAlH $\mathrm{H}_{1.1}$ powder enclosed in epoxy resin in order to prevent the hydrogen loss. Above $70 \mathrm{~K}$, the reciprocal magnetic susceptibility $X_{\mathrm{m}}{ }^{-1}$ of this hydride follows a CurieWeiss law $X_{\mathrm{m}}{ }^{-1}=\left(T-\theta_{\mathrm{p}}\right) / C_{\mathrm{m}}$ having as Curie constant $C_{\mathrm{m}}=0.65 \mathrm{emu} \mathrm{mol}^{-1}$ and a large and negative paramagnetic Curie temperature $\theta_{\mathrm{p}}=-44 \mathrm{~K}$. The effective magnetic moment $\mu_{\text {eff. }}=\left(8 C_{\mathrm{m}}\right)^{1 / 2}=2.3 \mu_{\mathrm{B}} /$ Ce-atom is smaller than that calculated for free $\mathrm{Ce}^{3+}$ ion $\left(2.54 \mu_{\mathrm{B}}\right)$. Similar investigation performed on CePtAl (before any treatment or even after hydrogen desorption) and gives $\mu_{\text {eff. }}=2.51 \mu_{\mathrm{B}} / \mathrm{Ce}$-atom and $\theta_{\mathrm{p}}=-37 \mathrm{~K}$.

The temperature dependence below $17 \mathrm{~K}$ of the magnetization of CePtAl and CePtAlH $\mathrm{H}_{1.1}$ is shown in Fig. 4. The curve obtained for CePtAl is similar to that observed previously by Kitazawa et al. [5]; the curve exhibits a strong increase at $T_{\mathrm{c}}=5.8(2) \mathrm{K}$. A similar behaviour is observed at $T_{\mathrm{c}}=11.6(2) \mathrm{K}$ for CePtAlH $\mathrm{H}_{1.1}$ hydride. In other words, the hydride has a Curie temperature twice greater than that determined for CePtAl. This fact is confirmed by the curves showing at low temperatures, the field dependence of the magnetization (Fig. 5); these are typical for a ferro- or ferrimagnetic material. At $4 \mathrm{~K}$, the remanence is $0.15 \mu_{\mathrm{B}} \mathrm{mol}^{-1}$ and the magnetization takes a low value of $0.5 \mu_{\mathrm{B}} \mathrm{mol}^{-1}$ in applied field $B=3.5 \mathrm{~T}$. This last value is weak compared to that expected $g_{\mathrm{J}} J=2.14 \mu_{\mathrm{B}} \mathrm{mol}^{-1}$ for $\mathrm{Ce}^{3+}$ ion which suggests that the magnetic ordering of $\mathrm{CePtAlH}_{1.1}$ is not purely ferromagnetic.

\section{Conclusion}

In conclusion, our study shows that CePtAl absorbs and desorbs hydrogen reversibly at $295 \mathrm{~K}$. This presents a potential interest for application around ambient temperature and pressure. The insertion of hydrogen induces both a structural transition and a strong increase of its ferro (ferri)magnetic character.

\section{References}

1. J.-L. Bobet, B. Chevalier, B. Darriet, M. Nakhl, F. Weill, J. Etourneau, J. Alloys Comp., 317-318 (2001), p. 67.

2. F. Hulliger, J. Alloys Comp., 196 (1993), p. 225.

3. A. Dönni, H. Kitazawa, P. Fischer, J. Tang, M. Kohgi, Y. Endoh, Y. Morii, J. Phys: Condens. Mat., 7 (1995), p. 1663.

4. H. Kitazawa, S. Nimori, J. Tang, F. Iga, A. Dönni, T. Matsumoto, G. Kido, Physica B, 237-238 (1997), p. 212.

5. H. Kitazawa, A. Dönni, L. Keller, J. Tang, F. Fauth, G. Kido, J. Solid State Chem., 140 (1998), p. 233.

6. J.-L. Bobet, S. Pechev, B. Chevalier, B. Darriet, J. Alloys Comp., 267 (1998), p. 136. 


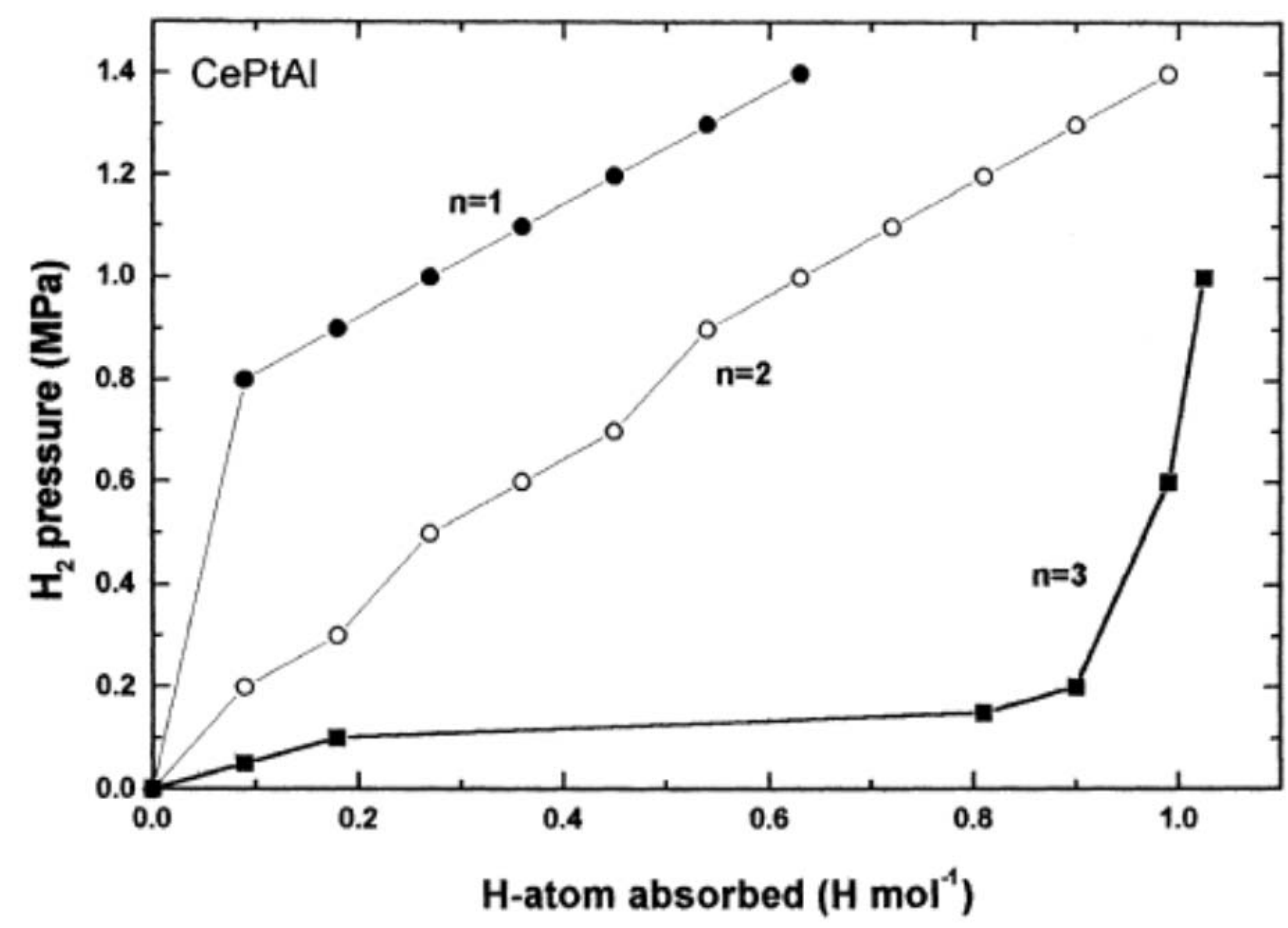

Fig. 1. Pression-composition curves for $\mathrm{CePtAl}$ at $295 \mathrm{~K}$ and various hydriding-dehydriding cycles $(n)$.

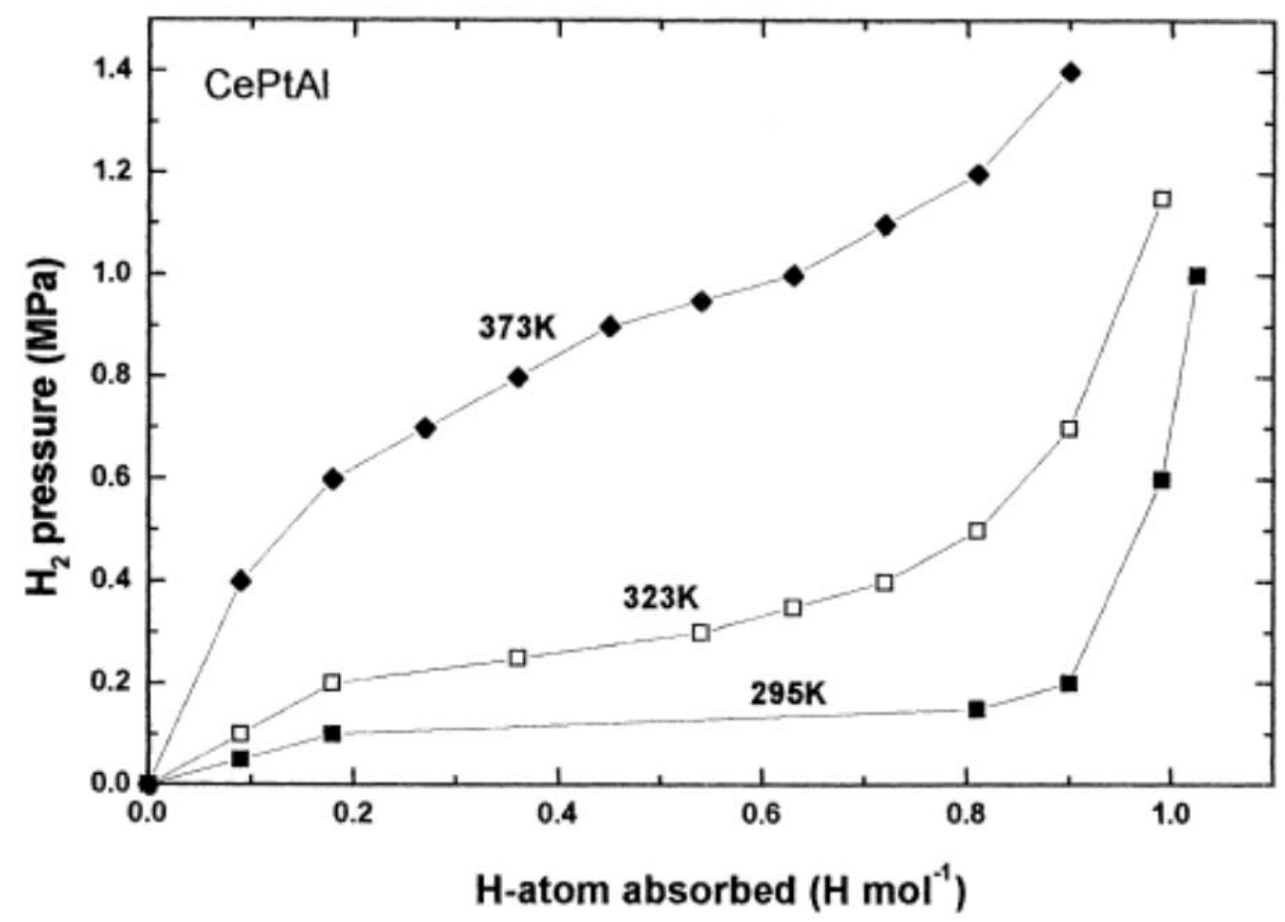

Fig. 2. Pression-composition curves for $\mathrm{CePtAl}$ at 295,323 and $373 \mathrm{~K}$. 


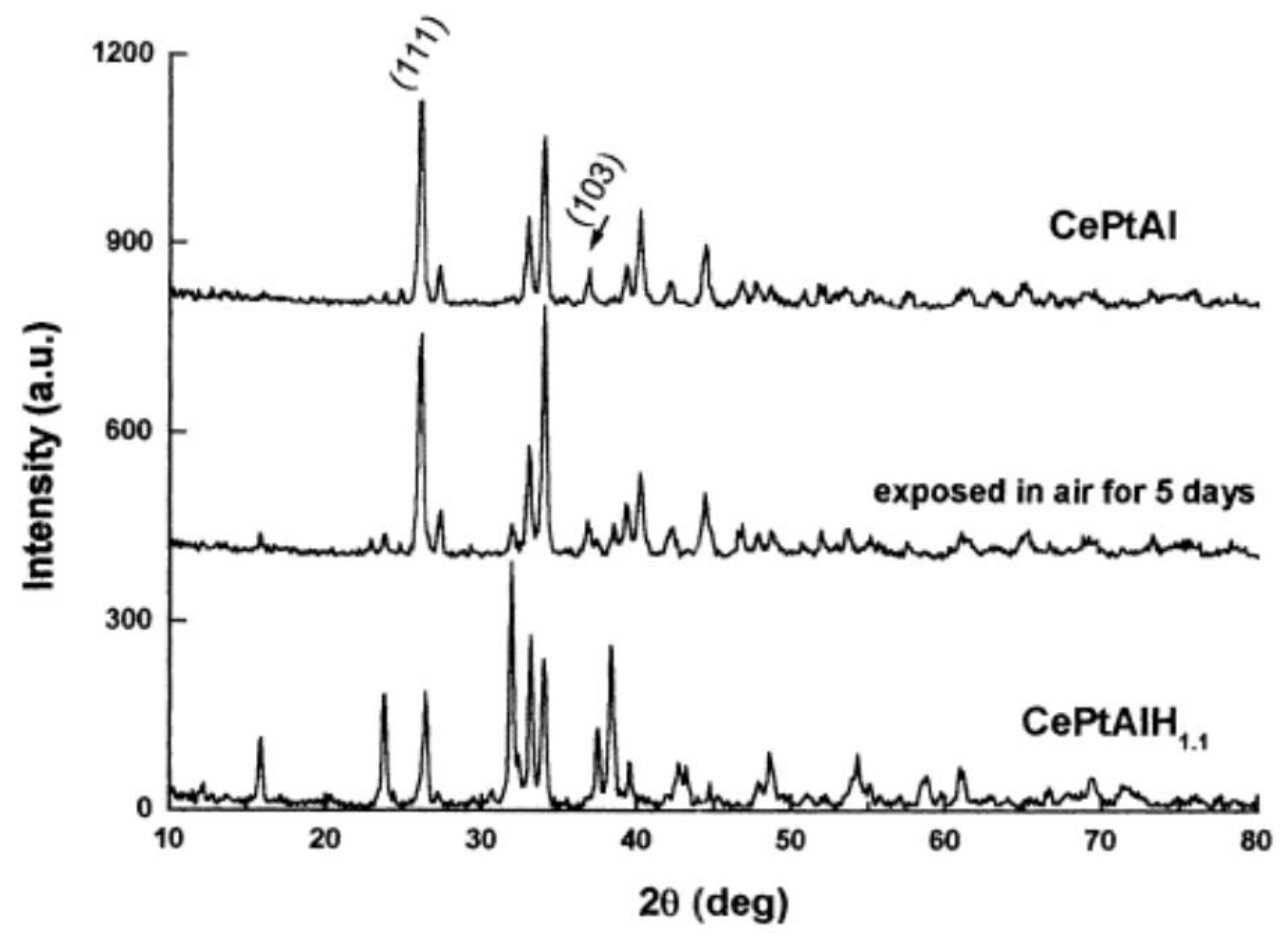

Fig. 3. X-ray powder pattern of $\mathrm{CePtAl}$ and $\mathrm{CePtAlH}_{1.1}$ before and after exposure in air for 5 days.

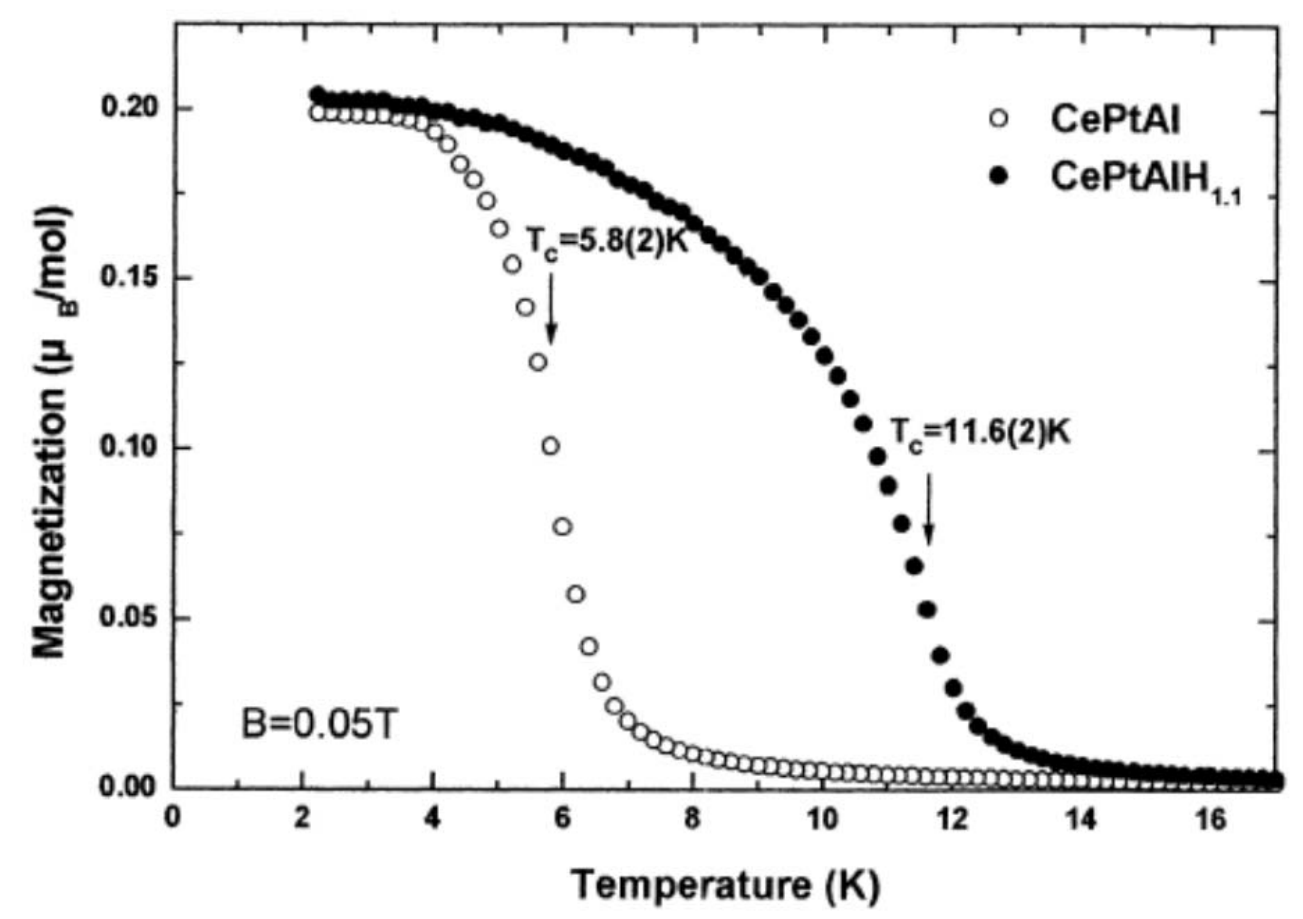

Fig. 4. Temperature dependence of magnetization, measured in an applied field of $B=0.05 \mathrm{~T}$, for $\mathrm{CePtAl}$ and $\mathrm{CePtAlH}_{1.1}$. 


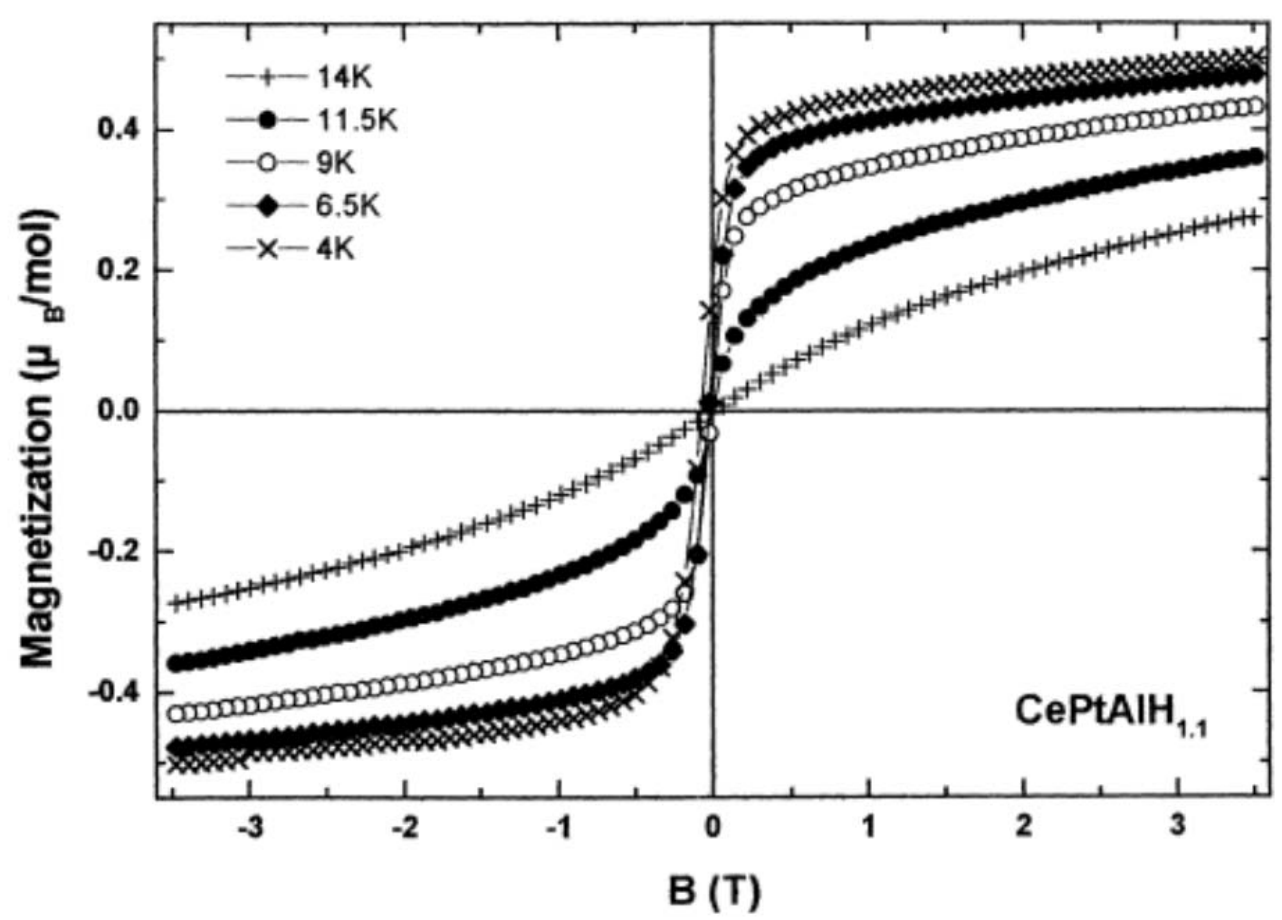

Fig. 5. Field dependence of magnetization for $\mathrm{CePtAlH}_{1.1}$ measured at various temperatures. 